\title{
Umpolung reactions at the $\alpha$-carbon position of carbonyl compounds
}

\author{
Okiko Miyata,* Tetsuya Miyoshi, and Masafumi Ueda \\ Kobe Pharmaceutical University, Motoyamakita, Higashinada, Kobe 658-8558, Japan \\ E-mail:miyata@kobepharma-u.ac.jp
}

Dedicated to Professor Richard R. Schmidt on the occasion of his $78^{\text {th }}$ anniversary

\begin{abstract}
Umpolung chemistry has been a focus of research in organic synthesis because of its usefulness and unusual reactivity. Above all, umpolung of enamine properties enables the formation of highly substituted carbon-carbon bonds and the installation of aryl groups which is difficult to achieve using normal enolate chemistry. This short review describes reports of carbon-carbon bond formation using umpolung reactions of enol and enamine derivatives.
\end{abstract}

Keywords: Umpolung, enamine, isoxazolidine, nitrosoalkene, vinylurea, sulfonylazoalkene

\section{Table of Contents}

1. Introduction

2. Umpolung Reactions of Tosylazoalkenes

3. Umpolung Reactions of Nitrosoalkenes

4. Umpolung Reactions of Vinylureas

5. Umpolung Reactions of $N$-Alkoxyenamines

6. Intramolecular Umpolung Reactions of $N$-Acyloxyenamides

7. Tandem Umpolung Reactions of Tosylalkenes

8. References

\section{Introduction}

Umpolung reactions have been developed as unconventional methods for the synthesis of target molecules. Polarity inversions of the carbonyl group are known in stoichiometric dithiane chemistry $^{1 \mathrm{a}-\mathrm{e}}$ and more recently in catalytic NHC ( $N$-heterocyclic carbene) chemistry, ${ }^{1 \mathrm{f}, \mathrm{g}}$ in which 
acyl anion equivalents generated by the umpolung reactivity of the carbonyl carbon react with an electrophile. ${ }^{2}$ A method involving the $\alpha$-alkylation and arylation of ketones is one conceptual approach for the synthesis of substrates bearing $\alpha$-substituted ketone moieties.

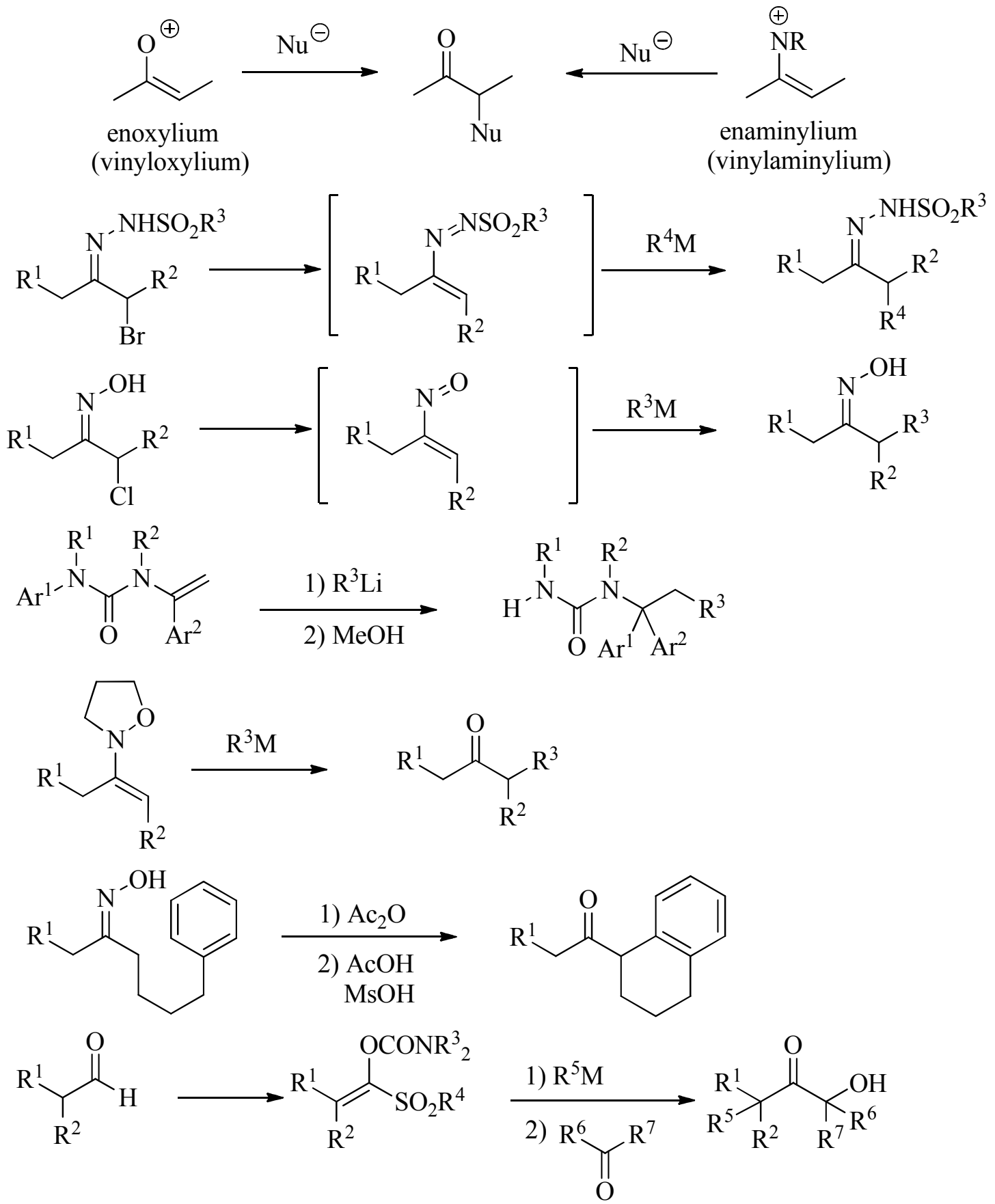

Scheme 1 
Generally, carbon-carbon bond formation at the $\alpha$-position of a ketone is performed by the reactions of enolates and enamines with carbon electrophiles. Carbon-carbon bond formation using a carbon nucleophile can be achieved if enoxylium and enaminylium ion equivalents can be produced in situ. The umpolung reaction of the $\alpha$-carbon on a carbonyl structure is an attractive reaction because it allows the direct introduction of various types of substituents into the $\alpha$-position through the use of nucleophiles. It is surprising that there are few publications on umpolung reactions at $\alpha$-carbon atoms, except for those on the use of $\alpha$-halogenated carbonyl compounds. ${ }^{3}$ In view of the potential advantages of umpolung reactions at $\alpha$-carbons, it is worthwhile discussing this emerging area.

This review concentrates on the umpolung reactions of enamine and enol derivatives. The known methods for the umpolung reactions of enamine and enol derivatives are summarized in Scheme 1. Two successful procedures for umpolung reactions of $N$-sulfonylazoalkenes ${ }^{4}$ with carbon nucleophiles, using conjugate addition, have been published (Eq. 1). Michael-type conjugate addition of nucleophiles to vinylnitroso compounds as enamines has been reported by Weinreb and co-workers ${ }^{5}$ (Eq. 2). Recently, a method for umpolung reactions, using vinylurea ${ }^{6}$ as the substrate, at the $\alpha$-position has been developed (Eq. 3). We have also reported nucleophilic arylations and alkylations of ketones by polarity inversion of $N$-alkoxyenamines (Eq. 4). ${ }^{7}$ Electrophilic aromatic substitution reactions of oximes have been described by Zard and coworkers, $^{8}$ as shown in Eq. 5. Hoppe and co-workers ${ }^{9}$ have reported the preparation of $\alpha, \alpha^{\prime}-$ branched $\alpha^{\prime}$-oxygenated ketones using tandem umpolung reactions of 1-(N,Ndialkylcarbamoyloxy)-1-tosylalkenes (Eq. 6).

\section{Umpolung reactions of tosylazoalkenes}

Fuchs $^{4 a}$ has explored a method for $\alpha$-arylation of carbonyl groups using $p$-toluenesulfonylazo alkenes $\mathbf{1 b}$ as the substrate. The tosylazoalkene $\mathbf{1 b}$ should be an excellent substrate for conjugated addition reactions. Specifically, reaction of $p$-toluenesulfonylazocyclohexene $\mathbf{1 b}$ prepared from the tosylhydrazone $\mathbf{2 b}$ with lithium diphenylcuprate or phenylcopper leads to complete consumption of the starting material within $1 \mathrm{~min}$ at $-60{ }^{\circ} \mathrm{C}$, concurrent with the production of pure $\alpha$-phenyltosylhydrazone $3 \mathbf{b}$ (70-75\%) (Scheme 2).

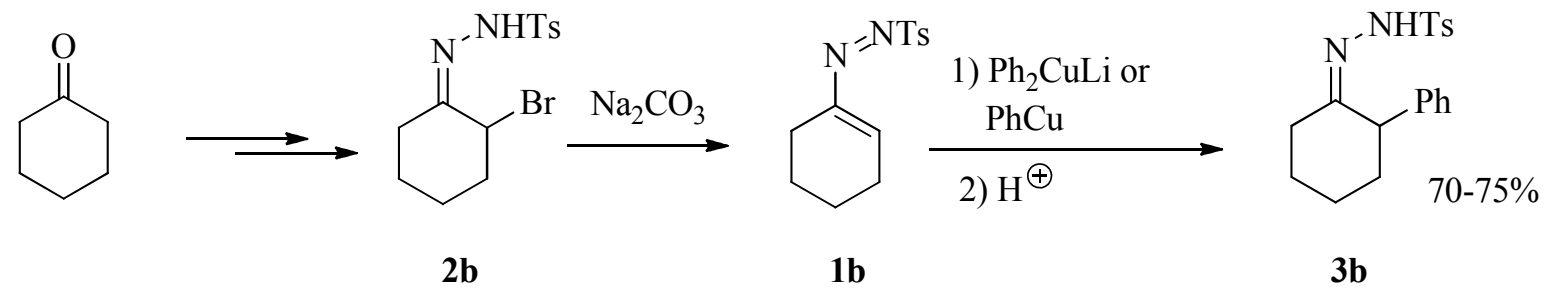

\section{Scheme 2}


The tosylazoalkene system $\mathbf{1 b}$ can be considered as an enamine derivative. Because the nucleophile reacts at the $\beta$-carbon of the enamine in this conjugate addition reaction, this Michael addition reaction can be considered to be a polarity inversion reaction of an enamine.

Since azoalkenes 1 may be generated in situ, there is no need to isolate them. The reactions of a series of $\alpha$-halotosylhydrazones $\mathbf{2}$ with an excess of phenylcopper smoothly produced the $\alpha$ phenyltosylhydrazones $\mathbf{3}$, which may be converted in high yield via carbonyl exchange to the corresponding $\alpha$-phenyl ketones 4 (Table 1).

Table 1. The conversion of $\alpha$-halohydrazones to $\alpha$-phenylcyclic ketones

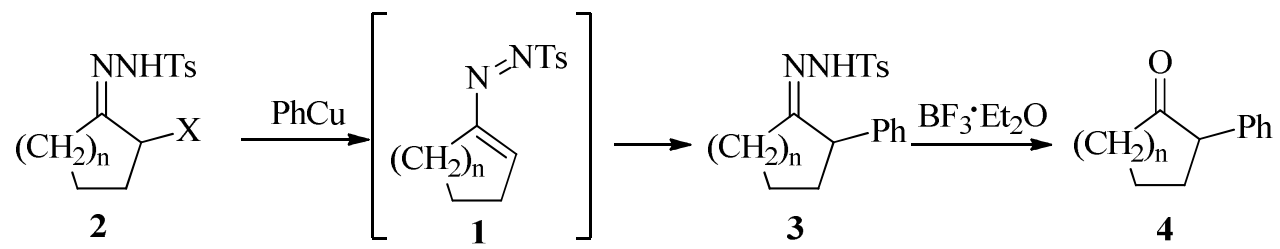

\begin{tabular}{ccccc}
\hline Substrate & $\mathrm{n}$ & $\mathrm{X}$ & Yield $(\%)$ of $\mathbf{3}$ & Yield (\%) of $\mathbf{4}$ \\
\hline $\mathbf{2 a}$ & 1 & $\mathrm{Cl}$ & 72 & 94 \\
$\mathbf{2 b}$ & 2 & $\mathrm{Br}$ & 75 & 95 \\
$\mathbf{2 c}$ & 3 & $\mathrm{Cl}$ & 77 & 88 \\
$\mathbf{2 d}$ & 4 & $\mathrm{Cl}$ & 87 & 83 \\
$\mathbf{2 e}$ & 8 & $\mathrm{Br}$ & 94 & 80 \\
\hline
\end{tabular}

The further utility of tosylazoalkenes as an enaminylium synthon is demonstrated in the reaction of $\alpha$-bromo- $\beta$-keto ester tosylhydrazones $\mathbf{5 a , b}$ with phenylcopper. Conceptually, the intermediates $\mathbf{6 a}, \mathbf{b}$ could either produce cinnamate esters $\mathbf{7 a , b}$ via $\beta$-phenyl addition or tosylhydrazones 8a,b via $\alpha$-addition. Examination of the product mixture revealed no detectable amounts of esters 7a,b. Hydrolysis of tosylhydrazones 8a,b by the usual method produced the corresponding $\alpha$-phenyl- $\beta$-keto esters in high yields (Scheme 3 ).

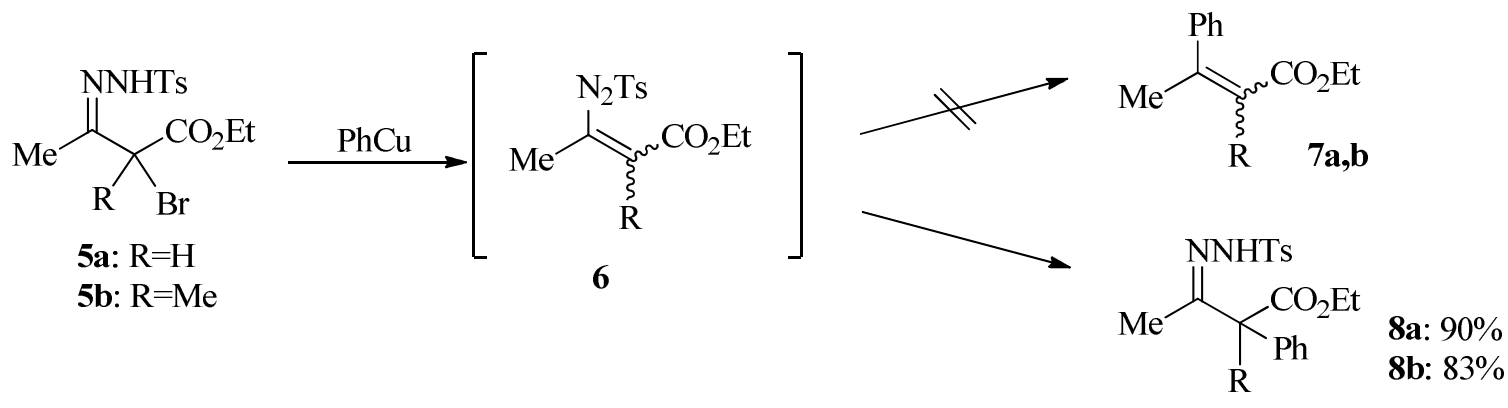

\section{Scheme 3}


Coltart $^{4 \mathrm{~b}}$ has extended the umpolung reactions of tosylazoalkenes with stoichiometric amounts of phenylcopper to copper(I)-catalyzed addition of Grignard reagents to $\mathrm{N}$-sulfonylazoalkenes. They anticipated the development of a copper(I)-catalyzed addition of Grignard reagents to in-situ-derived $N$-sulfonylazoalkenes, as outlined in Scheme 4.

An $\alpha$-halo- $N$-sulfonylhydrazine 9 is combined with at least 2 equiv of a Grignard reagent and a catalytic amount of a copper(I) salt. The Grignard reagent acts both as a Brønsted base to generate the azoalkene $(\mathbf{9} \rightarrow \mathbf{1 1})$ and undergoes in-situ transmetallation with the copper(I) catalyst to form a cuprate $\mathbf{1 4}$ capable of conjugate addition to 11. Transmetallation of the product 12 with $\mathrm{MgX}_{2}$ liberates the catalyst and 13, the latter providing the $\alpha$-alkylated product $\mathbf{1 0}$ on workup.

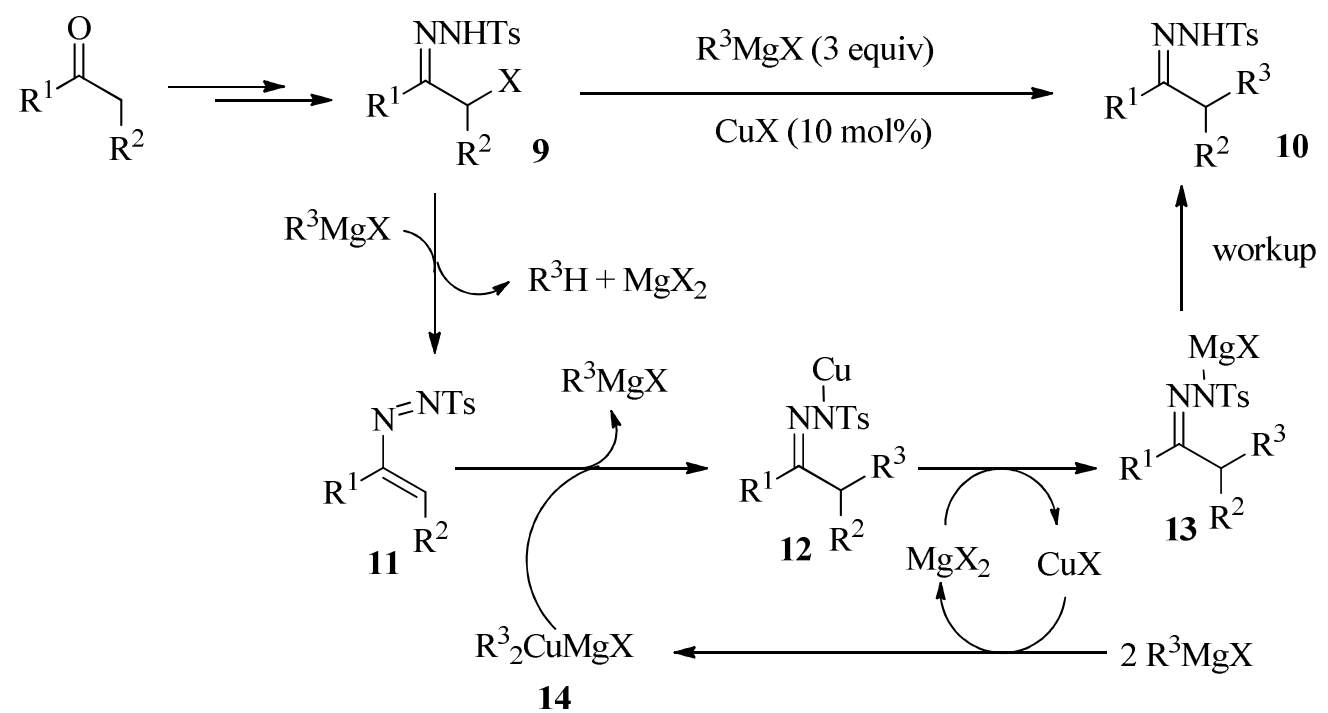

\section{Scheme 4}

The ethylation of $\alpha$-chloro- $N$-sulfonylhydrazone 15 with EtMgBr proceeds in the presence of catalytic amounts of a copper(I) salt to give $\alpha$-ethylhydrazine 16a. Secondary and tertiary Grignard reagents smoothly underwent the desired transformation (Scheme 5).

Using suitable alkylation conditions, the scope of the transformation was examined. Several different primary, secondary, and tertiary $\alpha$-chloro- $N$-sulfonylhydrazines, derived from both ketones and aldehydes, are suitable substrates for this reaction. 


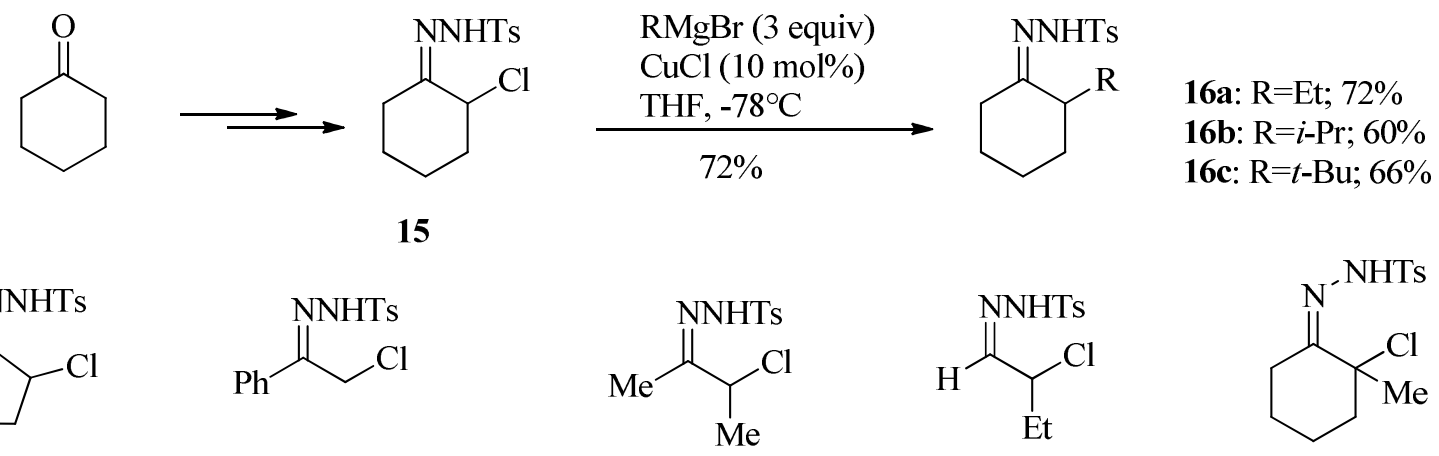

\section{Scheme 5}

The possibility of conducting one-pot $\alpha, \alpha$-dialkylations starting from $\alpha, \alpha$-dichloro- $N$ sulfonylhydrazones was investigated. The success of these transformations requires sequential elimination of chloride and addition of cuprate to the resulting azoalkene to occur twice, in a cascading fashion. The results are summarized in Table 2 . Treatment of different $\alpha, \alpha$-dichloro- $N$ sulfonylhydrazones with a Grignard reagent and a $\mathrm{CuCl}$ catalyst resulted in the incorporation of two identical alkyl groups (entries 1 and 2), indicating that two alkylations had occurred. Bisalkylation using two different Grignard reagents was also examined (entries 3-6).

Table 2. $\alpha, \alpha$-Bisalkylation of $\alpha, \alpha$-dichloro- $N$-sulfonylhydrazones

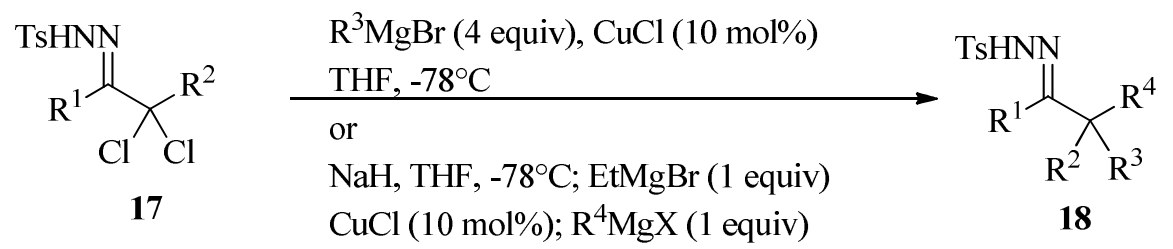

\begin{tabular}{cccccc}
\hline Entry & $\mathrm{R}^{1}$ & $\mathrm{R}^{2}$ & $\mathrm{R}^{3}$ & $\mathrm{R}^{4}$ & Yield (\%) \\
\hline 1 & $\mathrm{Me}$ & $\mathrm{Me}$ & $\mathrm{Et}$ & $\mathrm{Et}$ & 68 \\
2 & $\mathrm{H}$ & $\mathrm{Et}$ & $i-\mathrm{Pr}$ & $i-\mathrm{Pr}$ & 62 \\
3 & $\mathrm{Me}$ & $\mathrm{Me}$ & $\mathrm{Et}$ & $i-\mathrm{Pr}$ & 58 \\
4 & $\mathrm{Me}$ & $\mathrm{Me}$ & $\mathrm{Et}$ & $t-\mathrm{Bu}$ & 56 \\
5 & $\mathrm{H}$ & $\mathrm{Et}$ & $\mathrm{Et}$ & $t-\mathrm{Bu}$ & 56 \\
6 & $\mathrm{H}$ & $\mathrm{Et}$ & $\mathrm{Et}$ & $\mathrm{CH}_{2} t-\mathrm{Bu}$ & 52 \\
\hline
\end{tabular}

In each case, the desired bisalkylated compound bearing two different alkyl groups was generated. To investigate the possibility of coupling hydrazone oxidation with a catalytic alkylation reaction, $N$-sulfonylhydrazone 19 was treated with phenyltrimethylammonium tribromide to generate the $\alpha$-bromo- $N$-sulfonylhydrazone, ${ }^{10}$ and then exposed to catalytic 
alkylation conditions. The desired $\alpha$-alkylated product 16a was produced using this sequential transformation (Scheme 6).

The synthetic potential of this catalytic alkylation method was tested by carrying out a concise synthesis of the core framework of the natural product trichodiene ${ }^{11}$ (Scheme 6). Compound 20 was treated with 1-methylcyclopentylmagnesium chloride to produce 21 in $74 \%$ yield, enabling the direct linkage of the adjacent quaternary carbon centers in a single step.
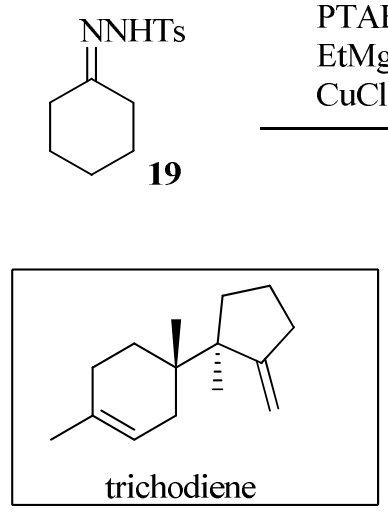

trichodiene

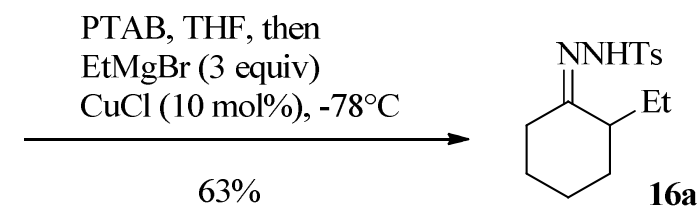<smiles>[Y15]C1(Cl)CCCCC1=N</smiles>

20
PTAB: phenyltrimethylammonium tribromide

\section{Scheme 6}

\section{Umpolung reactions of nitrosoalkenes}

Vinylnitroso compounds $\mathbf{2 2}$ are highly reactive, generally unstable species which have found only sporadic use in organic synthesis. There are presently two procedures commonly used to generate nitrosoalkenes 22 (Scheme 7). ${ }^{5 b}$

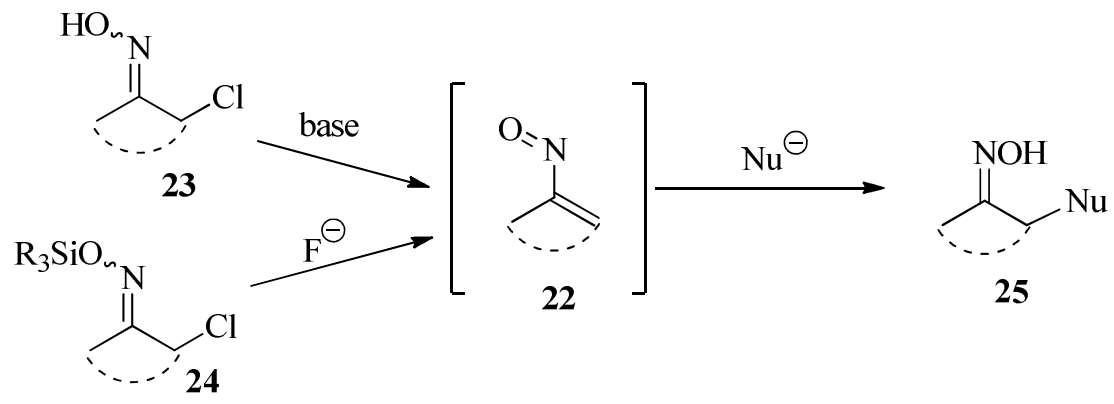

\section{Scheme 7}

The most widely used method involves base-promoted 1,4-elimination of an $\alpha$-halooxime $\mathbf{2 3}$ to produce the vinylnitroso species $\mathbf{2 2}$. These transient intermediates are known to undergo rapid 
conjugate additions with a variety of hetero and carbon nucleophiles in Michael-type reactions to produce adducts 25 in good yields. When forming vinylnitroso species 22 via this process, it is common to use at least two equivalents of the nucleophile, one of which acts as the base for the initial elimination step. Such a procedure, however, is inefficient when using expensive nucleophiles.

The second method for nitrosoalkene 22 generation involves the treatment of an $\alpha$-chloro- $O$ silyloxime $\mathbf{2 4}$ with a fluoride source to form $\mathbf{2 5}$.

Carbon nucleophiles that have been added to vinylnitroso compounds include electron-rich arenes and heteroarenes, ${ }^{12}$ malonates, ${ }^{13}$ 1,3-diketones, $\alpha$-keto esters, Grignard reagents, ${ }^{13}$ acetylides, ${ }^{13,14}$ and simple ketone enolates. ${ }^{15}$ Thus, vinylnitroso compounds 22 can act as enaminylium ion equivalents. Weinreb has reported that a diverse array of nitrosoalkenes derived from acyclic and cyclic ketones and aldehydes, using $\alpha$-chloro- $O$-TBS-oximes, can be trapped efficiently in situ using a wide variety of potassium enolates to afford conjugate addition products in good yields. The scope and limitations of this method have been explored (Table 3).

Table 3. Michael addition of carbon nucleophiles to nitrosoalkenes

entry


An ester derivative 26 (1.2 equiv) was first converted into its potassium enolate with potassium hexamethyldisilazide in THF at $-78{ }^{\circ} \mathrm{C}$. The addition of an $\alpha$-chloro- $O$-TBS-oxime 27 (1.0 equiv) to the enolate solution was followed by slow addition of tetrabutylammonium fluoride solution in THF (1.2 equiv). The mixture was then slowly warmed to $0{ }^{\circ} \mathrm{C}$, and after $2 \mathrm{~h}$ the reaction was worked up to yield alkylation products $\mathbf{2 8}$.

Michael-type conjugate additions of acyclic nitrosoalkenes 30 derived from $\gamma$-chiral aldoxime 29 have been explored using a series of carbon nucleophiles. In all cases examined, these reactions are stereoselective, leading exclusively to the anti-products $\mathbf{3 1}$ (Scheme 8). ${ }^{5 \mathrm{e}}$ The outcome of these nitroalkene additions can be rationalized based upon a Felkin-Anh-type transition state.

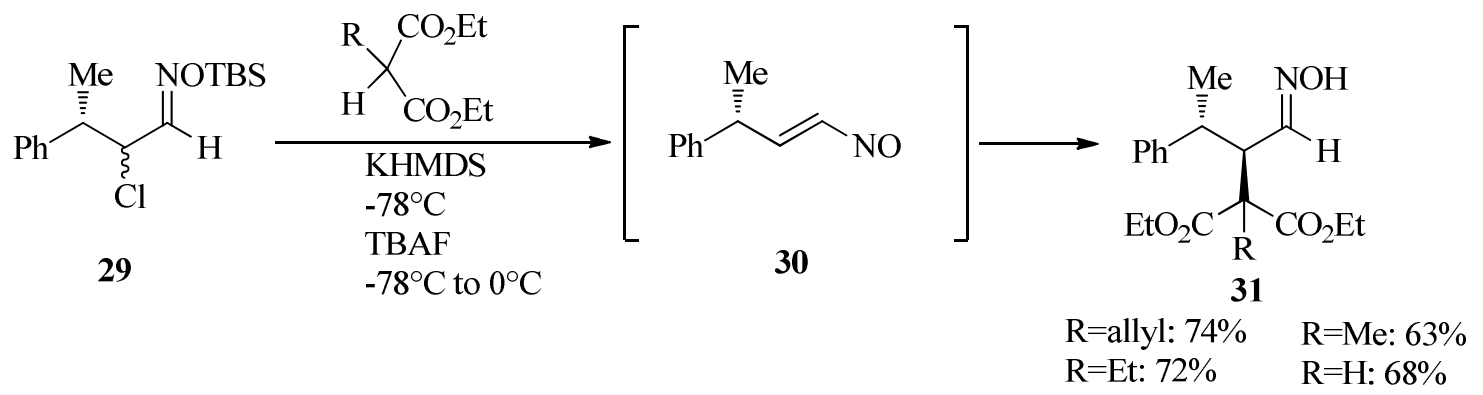

\section{Scheme 8}

Intermolecular Michael reactions of nitrosoalkenes have been applied to intramolecular reactions (Scheme 9). $\alpha$-Chloroketone 32 was first transformed into oxime derivative $\mathbf{3 3}$ using commercially available $O$-TBS-hydroxylamine. Compound $\mathbf{3 3}$ is a complex mixture of diastereomers, including oxime geometric isomers.

For the pivotal cyclization step, it is best initially to deprotonate the malonate $\mathbf{3 3}$ with sodium hexamethyldisilazide in THF at low temperature, followed by addition of tetrabutylammonium fluoride, leading to formation of the desired bicyclic oxime diester $\mathbf{3 5}$ in nearly quantitative yield. Compound $\mathbf{3 5}$ is a single stereoisomer with the (E)-oxime configuration. This cyclization occurred via the transient vinylnitroso intermediate 34 . The conversion of $\mathbf{3 5}$ to $\mathbf{3 6}$ could be conveniently effected using DMP (Dess-Martin periodinane). 


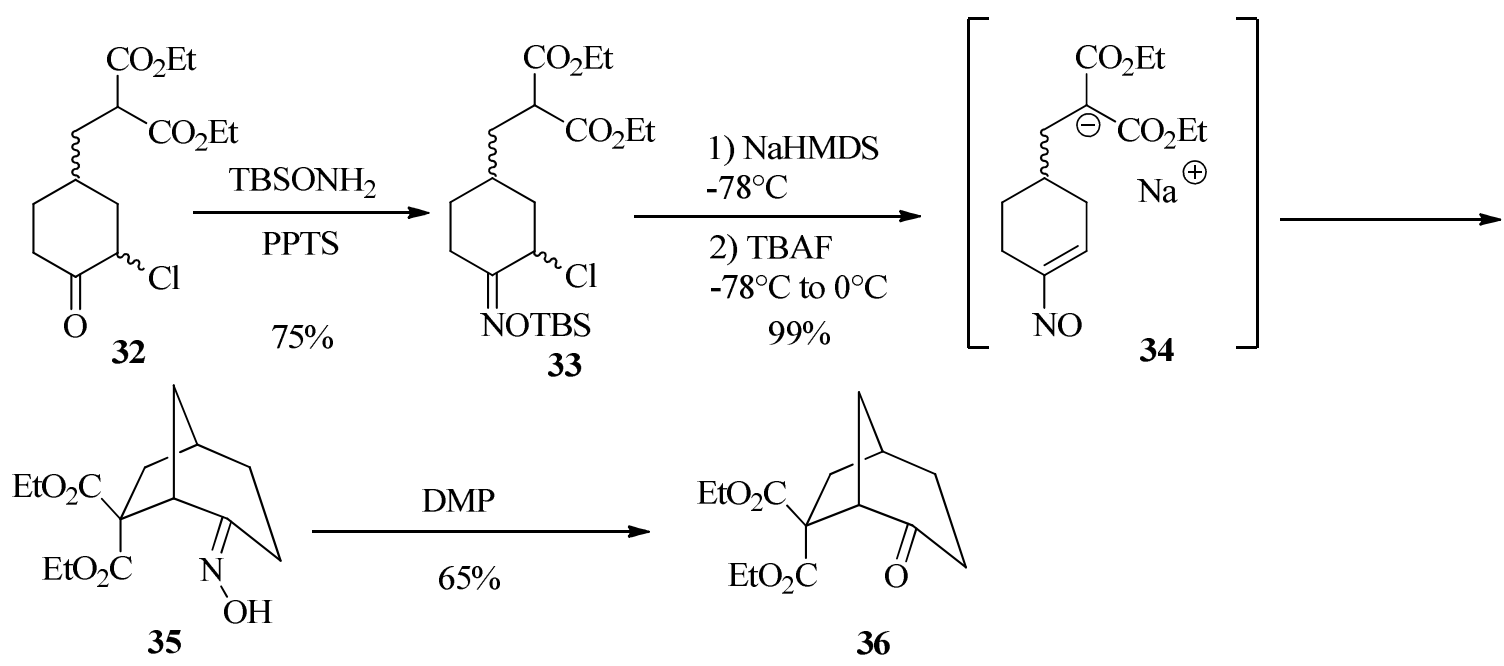

\section{Scheme 9}

\section{Umpolung reactions of vinylureas}

Clayden ${ }^{6}$ has reported that $N$-carbamoylenamines such as 38a ( $N$-alkenylureas) also exhibit umpolung reactivity, undergoing addition of organolithiums to their otherwise nucleophilic $\beta$ carbons (Scheme 10). Alkenylurea 38a, prepared by $N$-carbamoylation of imine 37, was treated with tert-butyllithium in THF for $1 \mathrm{~h}$ at $-78^{\circ} \mathrm{C}$. After the reaction was quenched with methanol, a single addition product 39a was obtained. On the other hand, upon treatment with less hindered organolithium $(n-\mathrm{BuLi})$, the rearranged product $41 \mathrm{a}$ was obtained by $\mathrm{N} \rightarrow \mathrm{C}$ migration of the $N$ phenyl ring of $\mathbf{4 0 a}{ }^{16,17}$ The product 41a was easily converted to the tertiary alkylamine $\mathbf{4 2 a}$ by heating in $n$-butanol, indicating that this "alkylarylation" of enamine 38a could constitute a useful new method for the construction of multiply branched alkylamines.

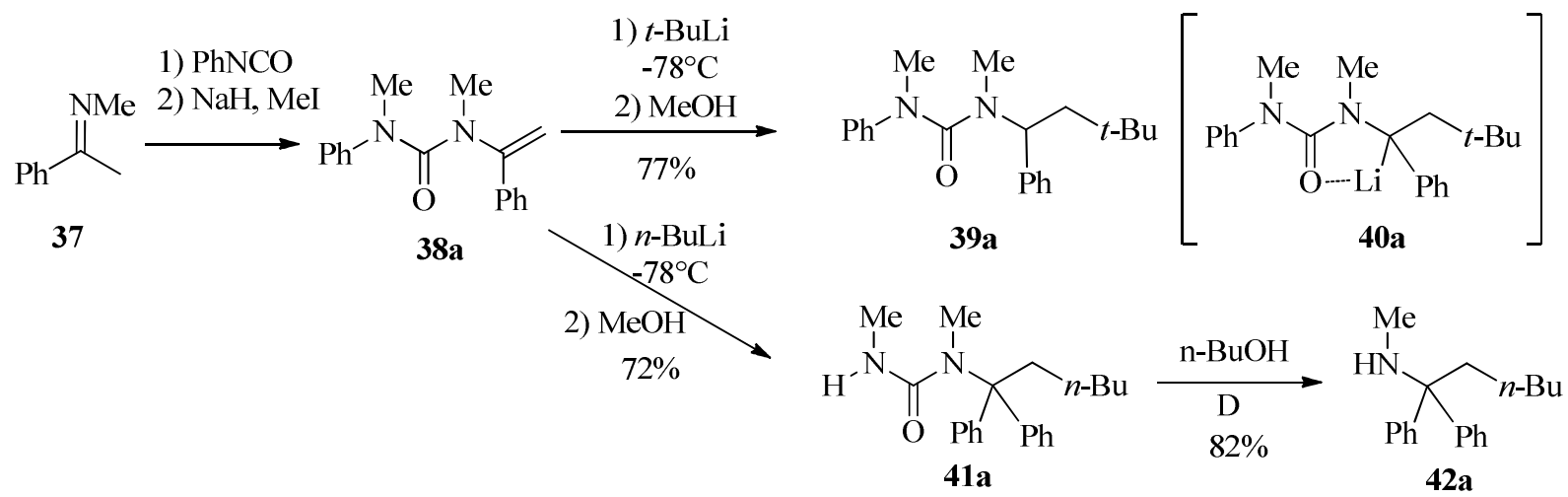

\section{Scheme 10}


Table 4. Organolithium addition to vinylureas

\begin{tabular}{|c|c|c|c|c|c|}
\hline & $\mathrm{A}$ & 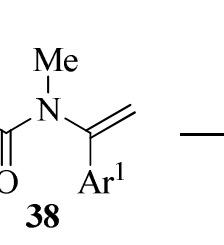 & $\begin{array}{l}\mathrm{RLi} \\
50^{\circ} \mathrm{C} \\
\mathrm{MeOH} \\
\end{array}$ & 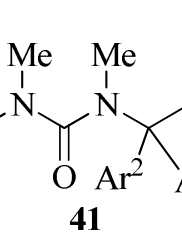 & \\
\hline Entry & Substrate & $\mathrm{Ar}^{1}$ & $\mathrm{Ar}^{2}$ & $\mathrm{R}$ & Yield (\%) \\
\hline 1 & 38a & $\mathrm{Ph}$ & $\mathrm{Ph}$ & $i-\operatorname{Pr}$ & 74 \\
\hline 2 & $38 \mathbf{a}$ & $\mathrm{Ph}$ & $\mathrm{Ph}$ & $\mathrm{Ph}$ & 77 \\
\hline 3 & $38 b$ & $\mathrm{Ph}$ & $p-\mathrm{MeOC}_{6} \mathrm{H}_{4}$ & $i-\operatorname{Pr}$ & 75 \\
\hline 4 & $38 c$ & $\mathrm{Ph}$ & $p-\mathrm{ClC}_{6} \mathrm{H}_{4}$ & $i-\operatorname{Pr}$ & 72 \\
\hline 5 & 38d & $p-\mathrm{MeOC}_{6} \mathrm{H}_{4}$ & $\mathrm{Ph}$ & $i-\operatorname{Pr}$ & 77 \\
\hline 6 & $38 \mathrm{e}$ & $p-\mathrm{ClC}_{6} \mathrm{H}_{4}$ & $\mathrm{Ph}$ & $i-\operatorname{Pr}$ & 86 \\
\hline 7 & $38 f$ & $p-\mathrm{MeC}_{6} \mathrm{H}_{4}$ & $\mathrm{Ph}$ & $\mathrm{CH}=\mathrm{CH}_{2}$ & 75 \\
\hline
\end{tabular}

Table 4 shows the results of treating $N$-vinylureas 38a-f with RLi. In each case, carbolithiation followed by $N$-aryl migration resulted in tandem addition of two carbon substituents, $\mathrm{R}$ and $\mathrm{Ar}^{2}$. Yields were good to excellent, and a range of substituents, including methyl-, $n$ - and sec-alkyl-, alkenyl-, and aryl-lithiums were successfully added to the ureas. Migration of an aryl ring gave the rearranged products 41. Unsaturated products were obtained by addition of vinyllithium (entry 7).

Isopropyllithium underwent clean addition to $(E)$-alkenylureas 42a,b and gave carbolithiation-rearrangement products $\mathbf{4 3 a}, \mathbf{b}$ as single diastereoisomers (Table 5, entries 1,2).

Table 5. Organolithium addition to vinylureas
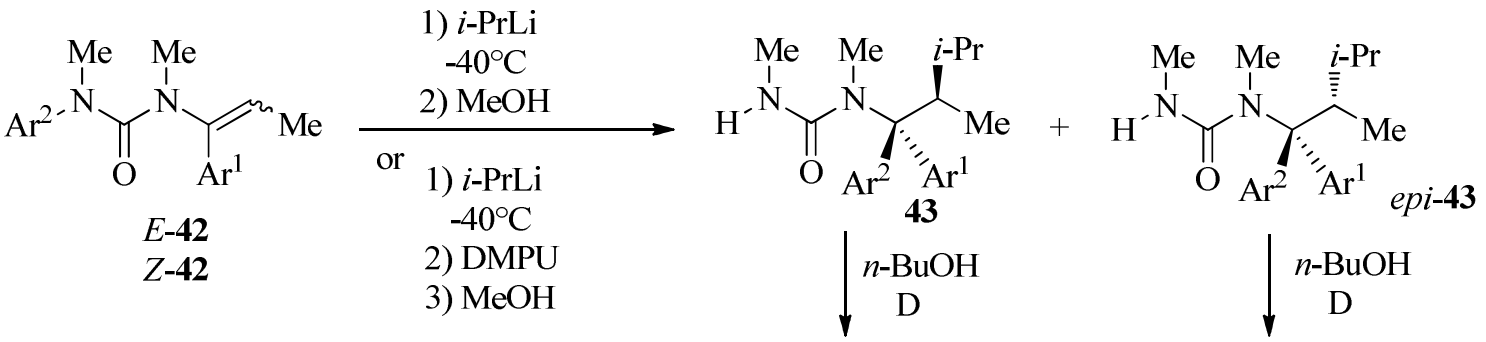

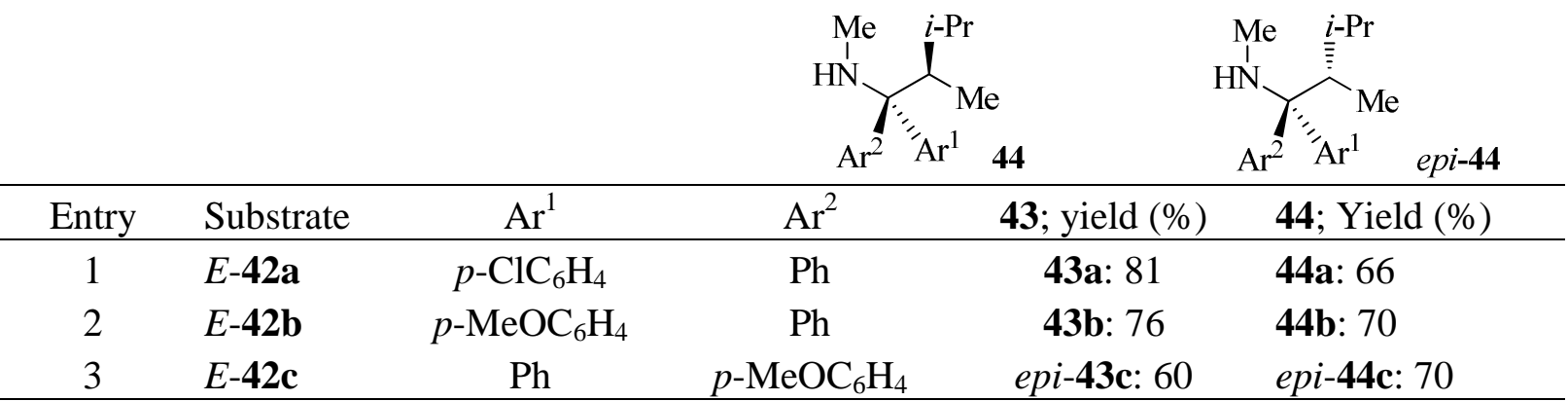




\begin{tabular}{llllll}
\hline 4 & $Z-42 a$ & $p-\mathrm{ClC}_{6} \mathrm{H}_{4}$ & $\mathrm{Ph}$ & epi-43a: 75 & epi-44a: 67 \\
\hline
\end{tabular}

Ureas 43a,b were readily converted to single diastereoisomers of the amines 44a,b in refluxing $n$-butanol. Migration of $\mathrm{Ar}^{1}$ and $\mathrm{Ar}^{2}$ within the starting material $(E)-\mathbf{4 2 c}$ led to an inversion of the relative configuration of the product epi-43c (entry 3). The epimeric product epi43a was also formed when the $E$ starting material 42a was replaced by the $Z$ isomer of 42a (entry 4).

Epimeric products were produced from $(E)$ - and $(Z)-\mathbf{4 2 a}$. Evidently, both the carbolithiation and aryl migration steps are stereospecific, since either inverting the double-bond geometry in the starting material or exchanging the substituents $\mathrm{Ar}^{1}$ and $\mathrm{Ar}^{2}$ changes the configuration of the products.

It is proposed that the reactions proceed by umpolung carbolithiation ${ }^{18}$ of $\mathbf{4 2}$ to give a substituted benzyllithium B via a stable complex A (Scheme 11). The benzyllithium $\mathbf{B}$ undergoes retentive $\mathrm{N} \rightarrow \mathrm{C}$ aryl migration by attack of the organolithium center on the $\mathrm{N}$-aryl ring $\mathrm{Ar}^{2} \mathbf{C}$, transferring $\mathrm{Ar}^{2}$ to the $\alpha$-position and yielding lithiourea $\mathrm{D}$, and hence $\mathbf{4 3}$ upon protonation.
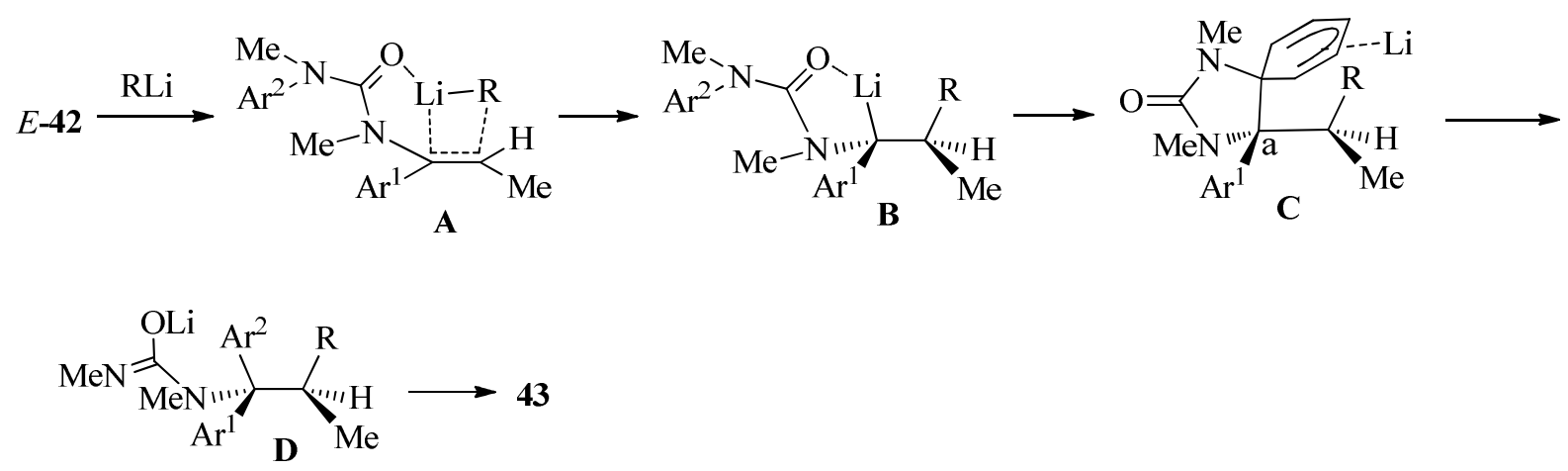

Scheme 11

\section{Umpolung reactions of $N$-alkoxyenamines}

Our research group ${ }^{7}$ has reported a strategy for the efficient umpolung $\alpha$-alkylation and $\alpha$ arylation of ketones via enamine intermediates (Scheme 12). Generally, enamine 46 (X = alkyl) reacts with an electrophile to give a 2 -substituted ketone 47 . The enamine 46 carrying a heteroatom substituent $(X=\mathrm{OR})$ generates the corresponding $\alpha$-carbonyl carbocation equivalent B by coordination with a Lewis acid followed by $\mathrm{N}-\mathrm{X}$ bond cleavage of the resulting complex A. The subsequent desired reaction with a nucleophile occurs at an electrophilic $\alpha$-carbon atom to form the imine, which is unstable enough to undergo hydrolysis upon aqueous workup.

The umpolung alkylations of various ketones with several commercially available $\mathrm{R}_{3} \mathrm{Al}$ (trialkylaluminium) compounds were investigated (Table 6). 


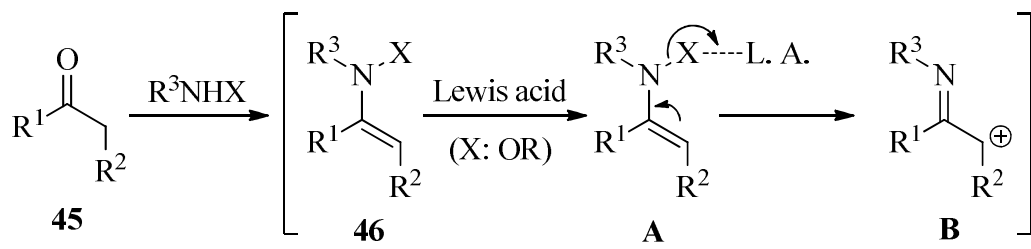<smiles>[R]C(=O)C([R])[I-]</smiles>

47

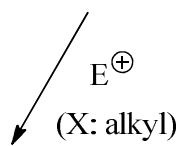

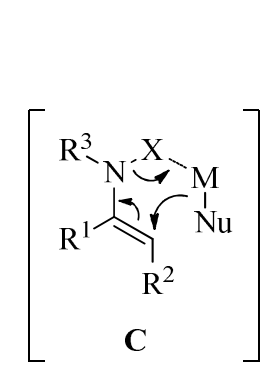

1) $\mathrm{Nu} \ominus$

2) aqueous

workup $\left(\mathrm{Nu}: \mathrm{R}, \mathrm{Ar}^{\ominus}\right)$<smiles>[R]C(=O)C([R])[NH3+]</smiles>

\section{Scheme 12}

Table 6. Umpolung alkylation of various ketones

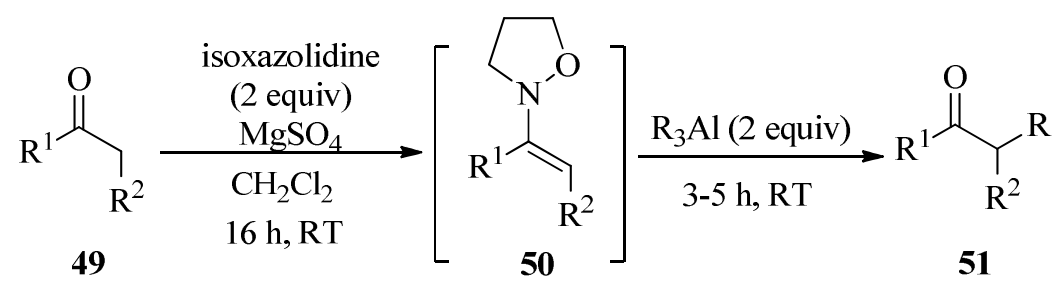

\begin{tabular}{|c|c|c|c|c|c|}
\hline Entry & Substrate & $\mathrm{R}$ & Product & & Yield ( \\
\hline 1 & & Et & & 51a: $\mathrm{R}=\mathrm{Et}$ & 76 \\
\hline 2 & & $i$-Bu & & 51b: $i-\mathrm{Bu}$ & 69 \\
\hline
\end{tabular}

3<smiles>CC1CCCCC1=O</smiles>

Et<smiles>[R]C1CCCC(C)C1=O</smiles><smiles>[R]C(CCC)C(=O)CC(C)C</smiles>

51d
4<smiles>CCCCC(=O)CC(C)CC</smiles>

$49 c$
Et

Et<smiles>[R]C(C(=O)CC)c1ccccc1</smiles> 
The reaction of the $\mathrm{N}$-cyclohexenylisoxazolidine intermediate 50a, which was formed in situ, with $\mathrm{Et}_{3} \mathrm{Al}$ proceeded to afford $\mathbf{5 1 a}$ in $76 \%$ yield (Table 6, entry 1). Similarly, the reaction of 49a with $i$ - $\mathrm{Bu}_{3} \mathrm{Al}$ gave $\mathbf{5 1 b}$ (Table 6 , entry 2). In the case of 2-methylcyclohexanone (49b), 2ethyl-6-methylcyclohexanone (51c) was obtained as a result of regioselective formation of trisubstituted $N$-alkoxyenamine $\mathbf{5 0 b}$ as an intermediate. The umpolung reaction using acyclic ketone 49c,d provided the corresponding ethylated products 51d,e in good yields (Table 6, entries 4 and 5).

Next, the one-pot double nucleophilic alkylation of 50a was investigated (Scheme 13).

The treatment of 50a with $\mathrm{Et}_{3} \mathrm{Al}$ and subsequent reaction with allylmagnesium bromide gave dialkylated amino alcohol 53. This result indicates that this umpolung reaction proceeds via intermediate imine 52. Finally, addition of allylmagnesium bromide to imine $\mathbf{5 2}$ gave the amine 53.<smiles>O=C1CCCCC1</smiles>

49a
1) isoxazolidine ( 2 equiv) $\mathrm{MgSO}_{4}, \mathrm{CH}_{2} \mathrm{Cl}_{2}$

2) $\mathrm{Et}_{3} \mathrm{Al}$ (2 equiv)

3) allyl $\mathrm{MgBr}$ (4 equiv)

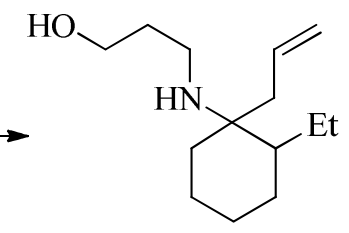

$53(46 \%)$<smiles>C[13CH][13CH]</smiles>

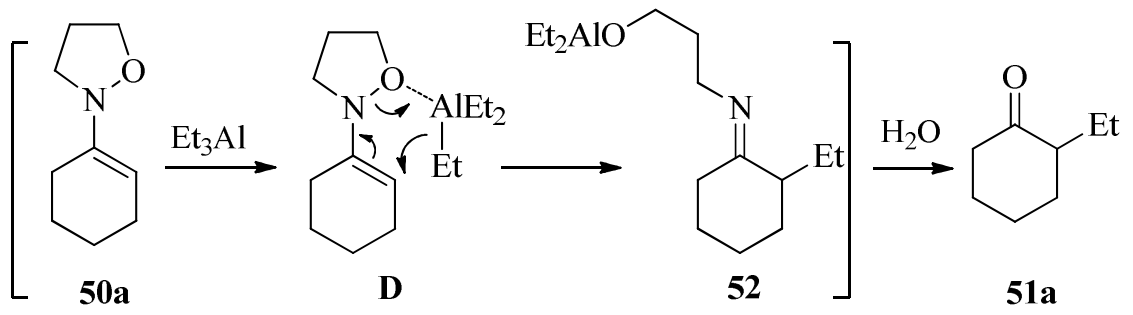

\section{Scheme 13}

This umpolung reaction was extended to $\alpha$-arylation (Table 7). The reaction using $\mathrm{Ph}_{3} \mathrm{Al}$ proceeded smoothly and gave $\alpha$-phenylated product 54a (Table 7, entry 1). The scope of $\mathrm{Ar}_{3} \mathrm{Al}$ compounds used was expanded (Table 7, entries 2-5). The electronic nature of the substituents on the benzene ring had little effect on the reaction efficiency. Higher yields of the desired $\alpha$-aryl ketone derivatives were observed when $N$-alkoxyenamine 50c was subjected to the arylation reaction (Table 7, entries 6-10).

Additionally, one-pot umpolung arylation reaction involving enamine formation was examined. Treatment of 5-nonanone (49c) with both isoxazolidine and $\mathrm{Ph}_{3} \mathrm{Al}$ in $\mathrm{CH}_{2} \mathrm{Cl}_{2}$ cleanly afforded the desired product $\mathbf{5 4}$ in $73 \%$ yield. Similar results were obtained when $\mathrm{Ar}_{3} \mathrm{Al}$ 
compounds such as p-tolyl-, 4-methoxylphenyl- and 4-fluorophenyl-Al reagents were employed. This method is equivalent to direct umpolung arylation of carbonyl compounds, which proceeds smoothly in the presence of isoxazolidine, and it provides an efficient alternative synthetic route to 2-arylcarbonyl compounds using a simplified procedure.

Table 7. Umpolung arylation of various ketones

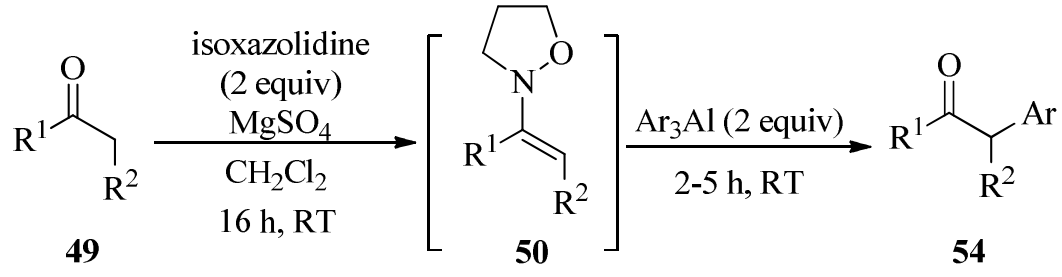

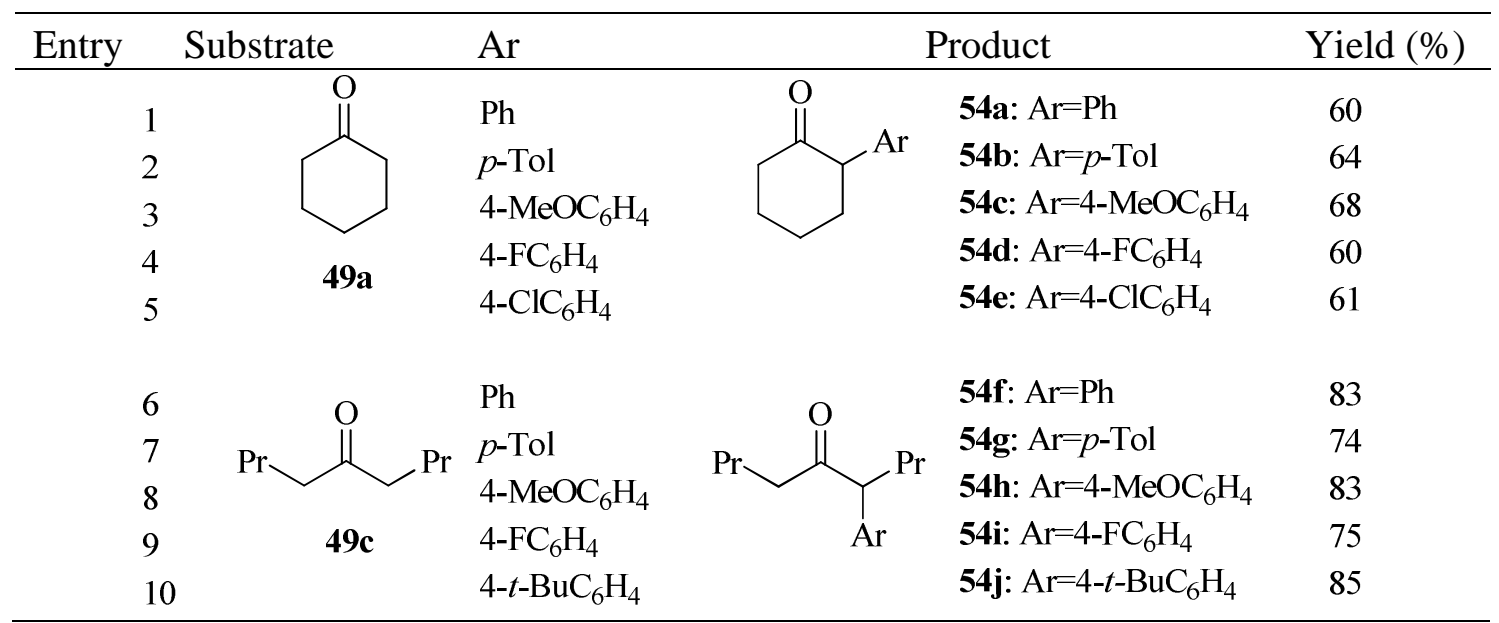

\section{Intramolecular umpolung reactions of $\mathrm{N}$-acyloxyenamides}

$\operatorname{Zard}^{8}$ has reported that the oximes 55 of 4-benzyltetralones undergo an electrophilic aromatic substitution reaction to form tetracyclic frameworks 57. It can be said that this reaction is equivalent to the polarity inversion reaction at the $\alpha$-carbon position of carbonyl compounds (Scheme 14).

Exposure of these oximes $\mathbf{5 5}$ to a combination of acetic anhydride and acetic acid/methanesulfonic acid furnished the corresponding tetracyclic ketones $\mathbf{5 7}$ in addition to variable amounts of the $N$-acetylnaphthylamines $\mathbf{5 6}$ resulting from the normal SemmlerWolff/Schroeter reaction. In most cases, the yield of the tetracyclic ketone was of the order 40$50 \%$. The presence of electron-donating methoxy groups caused significant reduction of the yield. 


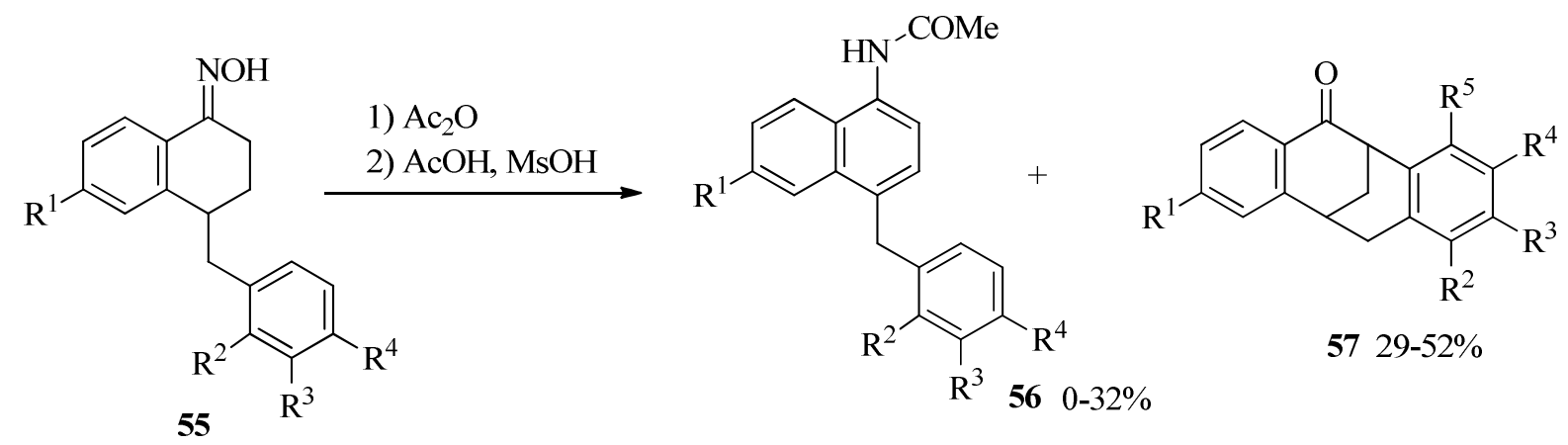<smiles>O=C1c2ccccc2C2Cc3ccccc3C1C2</smiles>

57a $52 \%$<smiles>COc1ccc2c(c1)C1CC(C2)c2ccccc2C1=O</smiles>

57b $29 \%$<smiles>O=C1c2ccccc2C2Cc3ccc(Br)cc3C1C2</smiles>

57c $49 \%$<smiles>Cc1ccc2c(c1)C1Cc3ccccc3C(C2)C1=O</smiles>

57d $50 \%$

\section{Scheme 14}

A plausible mechanism for the formation of tetracyclic derivatives $\mathbf{5 7}$ is shown in Scheme 15. The combination of acetic anhydride and methanesulfonic acid is sufficiently powerful to further acetylate oxime acetate 55a to give intermediate 58a, which is in equilibrium with enamide 59a. Enamide 59a would normally evolve into $N$-acetylnaphthylamide 56a by the Semmler-Wolff/Schroeter reaction. ${ }^{20}$ However, the presence of a pendant aromatic ring opens up another reaction pathway involving a Friedel-Crafts reaction, leading to acetylimine 60a. Hydrolysis during a basic workup would finally give ketone 57a.<smiles>CC(=O)O[N+](C(C)=O)=C1CCC(Cc2ccccc2)c2ccccc21</smiles>

\section{Scheme 15}


Evidence for such a pathway was obtained by modifying the workup procedure to avoid hydrolysis of intermediate 60a as far as possible. Thus, by diluting the crude reaction mixture with methanol, a very brief treatment with aqueous sodium bicarbonate, followed by separation of the organic layer, drying, evaporation, and rapid chromatography, furnished $N$-acetylimine 60a in $34 \%$ yield.

\section{Tandem umpolung reactions of tosylalkenes}

1-(N,N-Diisopropylcarbamoyloxy)-1-tosylalkenes $\mathbf{6 2}$ have been developed by Hoppe ${ }^{9}$ as substrates for tandem umpolung reactions. Upon addition of Grignard reagents and further quenching by carbonyl compounds, tosylalkenes 62 produce $\alpha, \alpha^{\prime}$-branched- $\alpha^{\prime}$-oxygenated ketones 66 (Scheme 16).
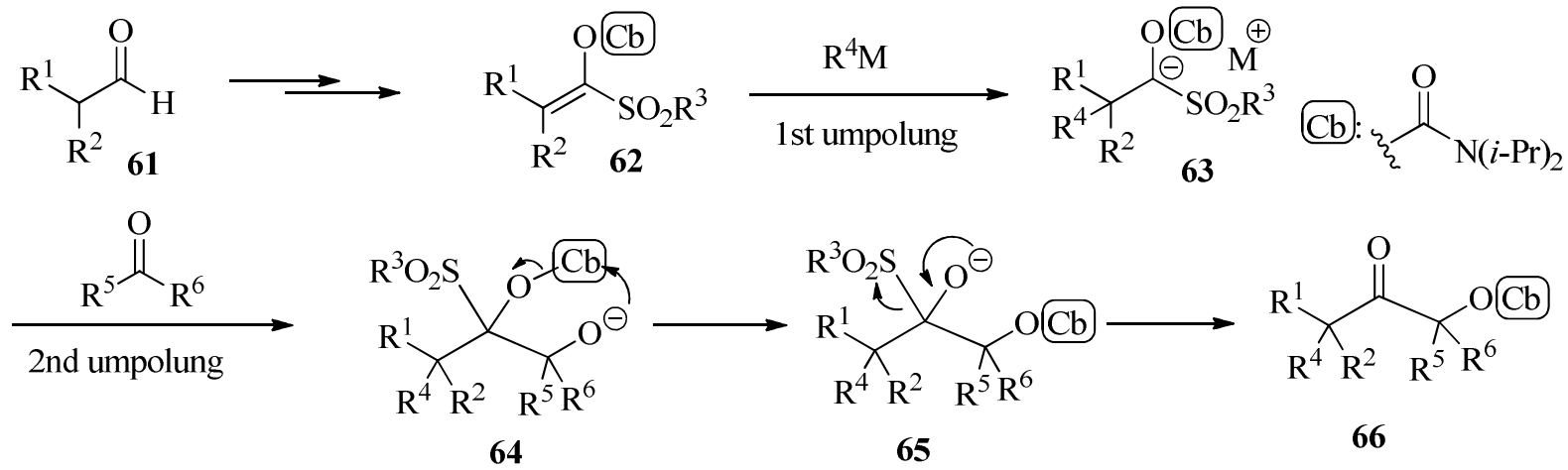

\section{Scheme 16}

Strategically, this method installs a carbanion unit and a carbonyl unit on the $\alpha$-carbon and the carbonyl center, respectively, of an aldehyde, in one-pot. As illustrated in Scheme 16, the C-1 position on 62 is regarded as a masked carbonyl group. When 62 is subjected to transition-metalcatalyzed addition reactions, a carbanion $\mathrm{R}^{4} \mathrm{M}$ could be added at the 2-position, which results in umpolung and generates 63 (first umpolung). Structure 63 can be further coupled with another carbonyl compound to form the substituted ketone $\mathbf{6 6}$ via migration of the carbamoyl group $(64 \rightarrow 65)$ and elimination of the sulfonyl group $(65 \rightarrow 66)$ (second umpolung). The first umpolung reaction is regarded as polarity inversion at the $\alpha$-carbon position of a carbonyl compound.

Virtually all common Grignard reagents gave moderate to excellent yields for the coppercatalyzed first addition to substrates 62a-d (Table 8). The results for alkyl, alkenyl, allylic, and aryl Grignard reagents are listed in Table 8. Less reactive Grignard reagents such as vinylmagnesium bromide or less reactive sulfone substrates such as $\mathbf{6 2 b}$ required higher 
temperatures or prolonged reaction times. Generally, the reaction temperature needs to be below $-20{ }^{\circ} \mathrm{C}$ to avoid decomposition of intermediate 63 .

Table 8. First umpolung reaction

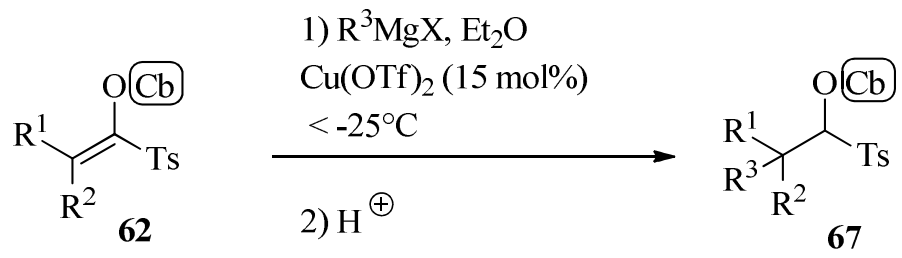

\begin{tabular}{ccccc}
\hline Substrate & $\mathrm{R}^{1}$ & $\mathrm{R}^{2}$ & $\mathrm{R}^{3}$ & Yield (\%) \\
\hline 62a & $\mathrm{H}$ & $\mathrm{H}$ & $\mathrm{Allyl}$ & 89 \\
62a & $\mathrm{H}$ & $\mathrm{H}$ & $i-\mathrm{Pr}$ & 79 \\
62b & $\mathrm{Me}$ & $\mathrm{H}$ & allyl & 57 \\
62b & $\mathrm{Me}$ & $\mathrm{H}$ & $\mathrm{Ph}$ & 47 \\
62c & $\mathrm{Ph}$ & $\mathrm{H}$ & $p-\mathrm{MeOC}_{6} \mathrm{H}_{4}$ & 70 \\
62c & $\mathrm{Ph}$ & $\mathrm{H}$ & allyl & 95 \\
\hline
\end{tabular}

Based on the knowledge obtained from the first addition, the first umpolung was extended to a tandem umpolung. (One can proceed to the second addition/migration/elimination to complete the tandem umpolung by quenching the magnesiated intermediate $\mathbf{6 3}$ with aldehydes or ketones.)

Table 9. Tandem umpolung reaction

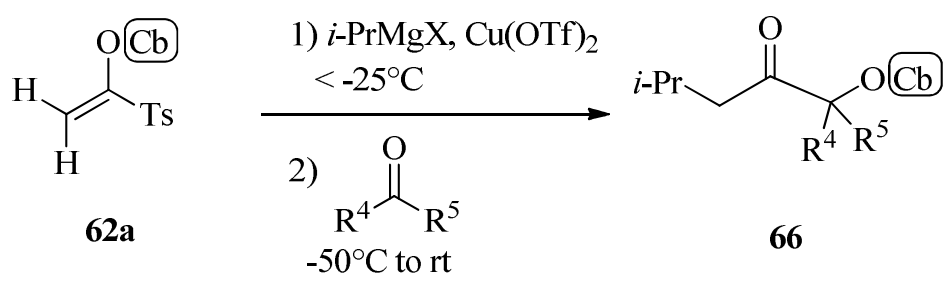

\begin{tabular}{ccc}
\hline $\mathrm{R}^{4}$ & $\mathrm{R}^{5}$ & Yield (\%) \\
\hline $\mathrm{Ph}$ & $\mathrm{H}$ & 78 \\
$p-\mathrm{MeOC}_{6} \mathrm{H}_{4}$ & $\mathrm{H}$ & 76 \\
$p-\mathrm{CF}_{3} \mathrm{C}_{6} \mathrm{H}_{4}$ & $\mathrm{H}$ & 80 \\
$2-$ pyridyl & $\mathrm{H}$ & 61 \\
$i-\mathrm{Pr}$ & $\mathrm{H}$ & 68 \\
$t-\mathrm{Bu}$ & $\mathrm{H}$ & 49 \\
\hline
\end{tabular}


As demonstrated in Table 9, benzaldehyde and substituted benzaldehydes gave excellent yields of the desired second addition/migration/elimination, but sterically hindered pivaldehyde gave moderate yields.

As indicated by the above experiments, a general and efficient procedure has been developed for the second addition/migration/elimination to complete the desired tandem umpolung. Combined with certain additives, the mild magnesiated sulfone $\mathbf{6 3}$ allows various aldehydes to be used in this procedure to generate $\alpha, \alpha^{\prime}$-branched- $\alpha^{\prime}$-oxygenated ketones as useful building blocks in moderate to excellent yields.

\section{References}

1. (a) Gröbel, B. T.; Seebach, D. Synthesis 1977, 357. (b) Seebach, D. Angew. Chem. Int. Ed. 1979, 18, 239. (c) Chen, Y.-L.; Leguijt, R.; Redlich, H. Synthesis 2006, 2242; (d) Chen, Y.L.; Leguijt, R.; Redlich, H.; Fröhlich, R. Synthesis 2006, 4212; (e) Chen, Y.-L.; Redlich, H.; Bergander, K.; Fröhlich, R. Org. Biomol. Chem. 2007, 5, 3330; (f) Marion, N.; DíezGonzález, S.; Nolan, S. P. Angew. Chem. Int. Ed. 2007, 46, 2988. (g) D. Enders, D.; Niemeier, O.; Henseler, A. Chem. Rev. 2007, 107, 5606.

2. Recent reviews of acyl anion equivalents: (a) Brehme, R.; Enders, D.; Fernandez, R.; Lassaletta, J. M. Eur. J. Org. Chem. 2007, 34, 5629. (b) Johnson, J. S. Curr. Opin. Drug Disc. 2007, 10, 691.

3. (a) Fu, G. C.; Lundin, P. M. J. Am. Chem. Soc. 2010, 132, 11027. (b) Fu, C. G.; Lou, S. J. Am. Chem. Soc. 2010, 132, 5010. (c) Lou, S.; Fu, G. C. J. Am. Chem. Soc. 2010, 132, 1264. (d) Dai, X.; Strotman, N. A.; Fu, G. C. J. Am. Chem. Soc. 2008, 130, 3302. (e) Studte, S.; Breit, B. Angew. Chem., Int. Ed. 2008, 47, 5451. (f) Furstner, A.; Martin, R.; Krause, H.; Seidel, G.; Goddard, R.; Lehmann, C. W. J. Am. Chem. Soc. 2008, 130, 8773. (g) Ohmiya, H.; Yorimitsu, H.; Oshima, K. J. Am. Chem. Soc. 2006, 128, 1886. (h) Malosh, C. F.; Ready, J. M. J. Am. Chem. Soc. 2004, 126, 10240. (i) Recent review of umpolung strategy of enamines: Tanimoto, H. Yuki Gosei Kagaku Kyokaishi 2011, 69, 823.

4. (a) Sacks, C. E.; Fuchs, P. L. J. Am. Chem. Soc. 1975, 97, 7372. (b) Hatcher, J. M.; Coltart, D. M. J. Am. Chem. Soc. 2010, 132, 4546.

5. (a) Korboukh, I.; Kumar, P.; Weinreb, S. M. J. Am. Chem. Soc. 2007, 129, 10342. (b) Li, P.; Majireck, M.; Witek, J. A.; Weinreb, S. M. Tetrahedron 2011, 67, 8229. (c) Li, P.; Majireck, M. M.; Witek, J. A.; Weinreb, S. M. Tetrahedron Lett. 2010, 51, 2032. (d) Kumar, P.; Li, P.; Korboukh, I.; Wang, T. L.; Yennawar, H.; Weinreb, S. M. J. Org. Chem. 2011,76, 2094. (e) Witek, J. A.; Weinreb, S. M. Org. Lett. 2011, 13, 1258.

6. (a) Clayden, J.; Donnard, M.; Lefranc, J.; Minassi, A.; Tetlow, D. J. J. Am. Chem. Soc. 2010, 132, 6624. (b) Tetlow, D. J.; Hennecke, U.; Raftery, J.; Waring, M. J.; Clarke, D. S.; Clayden, J. Org. Lett. 2010, 12, 5442.

7. Miyoshi, T.; Miyakawa, T.; Ueda, M.; Miyata, O. Angew. Chem. Int. Ed. 2011, 50, 928. 
8. Quiclet-Sire, B.; Toelle, N.; Zafar, S. N.; Zard, S. Z. Org. Lett. 2011, 13, 3266.

9. Chen, Y.-L.; Hoppe, D. J. Org. Chem. 2009, 74, 4188.

10. Rosini, G.; Baccolini, G. J. Org. Chem. 1974, 39, 826.

11. (a) Schlessinger, R. H.; Schultz, J. A. J. Org. Chem. 1983, 48, 407. (b) Snowden, R. L.; Brauchli, R.; Sonnay, P. Helv. Chim. Acta 1989, 72, 570. (c) Tanaka, M.; Sakai, K. Tetrahedron Lett. 1991, 32, 5581. (d) Kitano, Y.; Fukuda, J.; Chiba, K.; Tada, M. J. Chem. Soc., Perkin Trans. 1 1996, 829. (e) Lange, G. L.; Furlan, L.; MacKinnon, M. C. Tetrahedron Lett. 1998, 39, 5489.

12. Plate, R.; Hermkens, P. H. H.; Smits, J. M. M.; Nivard, R. J. F.; Ottenheijm, H. C. J. J. Org. Chem. 1987, 52, 1047.

13. Ohno, M.; Torimitsu, S.; Naruse, N.; Okamoto, M.; Sakai, I. Bull. Chem. Soc. Jpn. 1966, 39, 1129.

14. Trost, B. M.; Barrett, D. Tetrahedron 1996, 52, 6903.

15. Oppolzer, W.; Battig, K.; Hudlicky, T. Tetrahedron 1981, 37, 4359.

16. (a) Clayden, J.; Dufour, J.; Grainger, D.; Helliwell, M. J. Am. Chem. Soc. 2007, 129, 7488.

(b) Clayden, J.; Hennecke, U. Org. Lett. 2008, 10, 3567. (c) Bach, R.; Clayden, J.; Hennecke, U. Synlett 2009, 421.

17. Clayden, J.; Farnaby, W.; Grainger, D. M.; Hennecke, U.; Mancinelli, M.; Tetlow, D. J.; Hillier, I.; Vincent, M. J. Am. Chem. Soc. 2009, 131, 3410.

18. For related carbolithiations of acylated enols and enamines, see: (a) Peters, J. G.; Seppi, M.; Fro“hlich, R.; Wibbeling, B.; Hoppe, D. Synthesis 2002, 381. (b) Cottineau, B.; Gillaizeau, I.; Farard, J.; Auclair, M.-C.; Coudert, G. Synlett 2007, 1925. (c) Lepifre, F.; Cottineau, B.; Mousset, D.; Bouyssou,P.; Coudert, G. Tetrahedron Lett. 2004, 45, 483.

19. 19. Ahmed, M. G.; Ahmed, S. A.; Hickmott, P. W. J. Chem. Soc. Perkin Trans. 1 1980, 2383.

20. (a) Wolff, L. Justus Liebigs Ann. Chem. 1902, 322, 351. (b) Schroeter, G.; Gluschke, A.; Goetzky, S.; Huang, J.; Irmisch, G.; Laves, E.; Schrader, O.; Stier, G. Ber. Dtsch. Chem. Ges. 1930, 63, 1308. 


\section{Biographical Sketches}

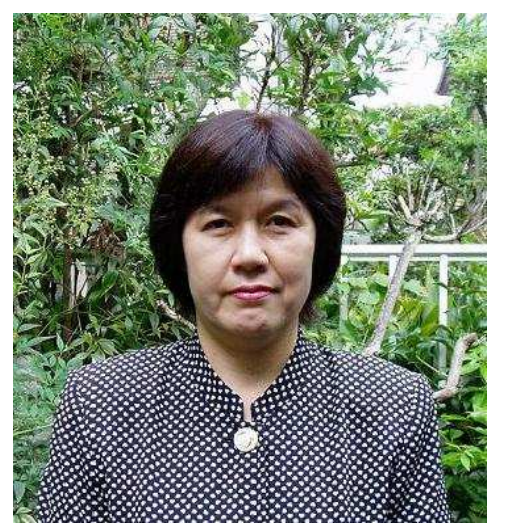

Okiko Miyata is Professor of Kobe Pharmaceutical University. She received her B. Sc. (1973) from Kobe Pharmaceutical University and Ph. D. degree (1979) from Osaka University. She became an Assistant Professor of Kobe Pharmaceutical University in 1976 and was promoted to Associate Professor in 2001 and Professor in 2008. She worked as a postdoctoral fellow of Alexander von Humboldt-Stiftung $(\mathrm{AvH})$ with Professor R. R. Schmidt at Konstanz University for one year from 1981. She received The Society of Synthetic Organic Chemistry, Japan Kansai-Branch Award in 2005. Her research interests are in the areas of synthetic organic chemistry, medicinal, and bioorganic chemistry.

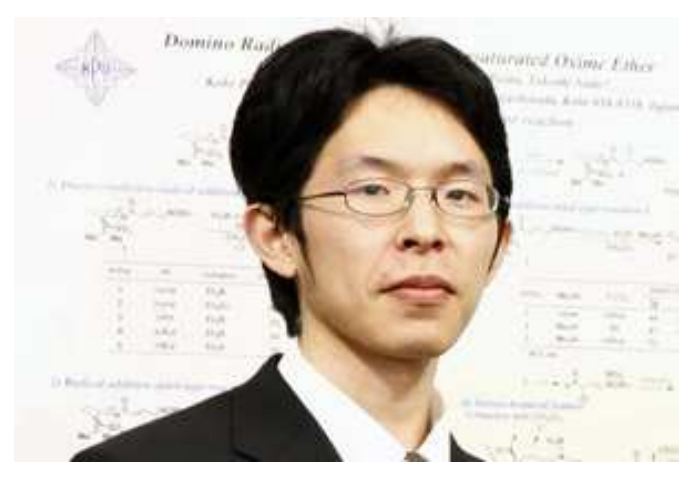

Tetsuya Miyoshi received his B. Sc. (2006) and M. Sc. (2009) from Osaka University under the supervision of Prof. Takeshi Imanishi and Prof. Satoshi Obika. Since 2009, he has been a research assistant at Kobe Pharmaceutical University. His research interests include development of new synthetic methodologies and design of molecular recognition elements. 


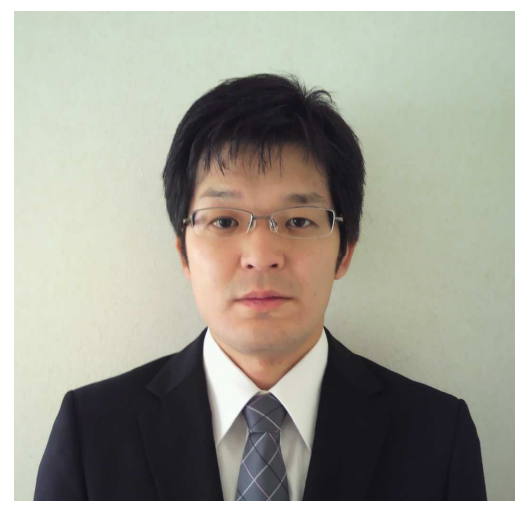

Masafumi Ueda graduated from Kobe Pharmaceutical University in 1999. He received PhD degree from Osaka University in 2006. He was appointed as research assistant of Kobe Pharmaceutical University in the research group of Profs. Takeaki Naito and Okiko Miyata. He was promoted to Assistant Professor in 2001 and lecturer. During this period, he joined Prof. Peter Wipf group at Pittsburgh University as a postdoc associate (2007-2008). He received awards The Pharmaceutical Society of Japan Kansai-Branch Award for Young Scientists in 2004, Fuji Photo Film Award in Synthetic Organic Chemistry, Japan in 2005 and Mitsubishi Chemical Award in Synthetic Organic Chemistry, Japan in 2012. His research interests include development of new synthetic methodology by using radical chemistry, transition metal catalysis, and the design and synthesis of bioactive compounds with pharmaceutical applications. 